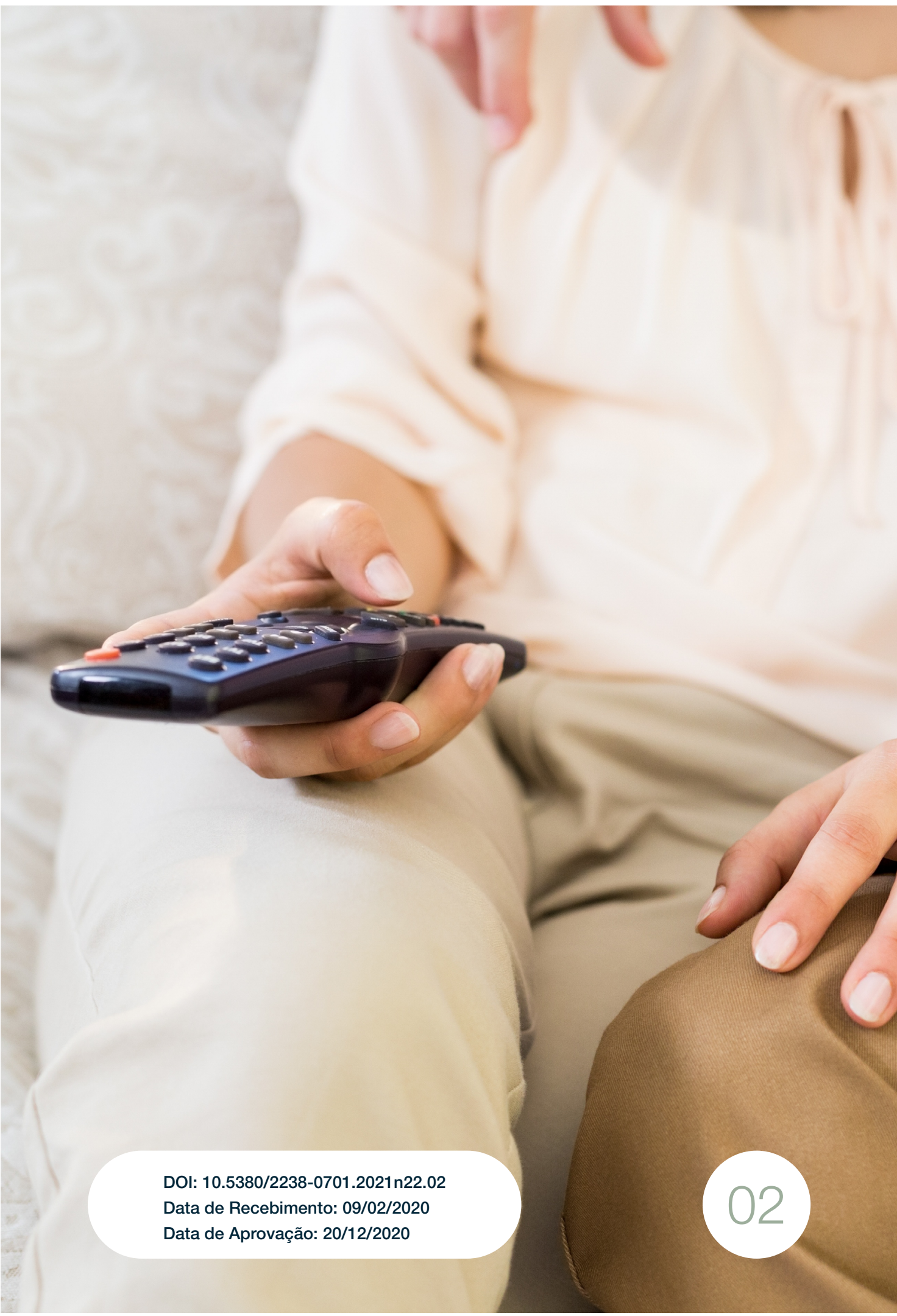


Dinâmicas na Circulação de Memes em Fandoms de Séries Televisivas 


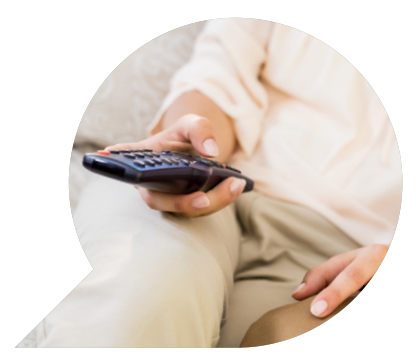

\title{
Dinâmicas na Circulação de Memes em Fandoms de Séries Televisivas
}

\author{
Dynamics in the Circulation of Memes in \\ TV Series' Fandoms
}

Dinámica en la Circulación de Memes en Fandoms de Series de Televisión

DANIEL RIOS ${ }^{1}$

Resumo: Fãs de séries televisivas se utilizam amplamente dos sites de redes sociais como ferramenta para compartilhar materiais produzidos por eles, tornando cada vez mais complexa a relação entre a televisão e o meio digital. Nesse contexto, este artigo se propõe a analisar que tipos de memes circulam em comunidades de fãs de ficções seriadas televisivas. Para isso, foi feita uma pesquisa em dois fandoms brasileiros de séries estadunidenses, Grey's MiiL gRaU e Game of Thrones Brasil L\&S. Enquadrando-os como um tipo particular de produção de fãs, argumenta-se que os memes compartilhados nesses espaços poderiam ser categorizados a partir de duas classificações: memes intratextuais, que falam sobre o objeto cultural no qual o fandom é centrado; e memes extratextuais,

1 Doutorando em Comunicação pelo PPGCOM-UFF e membro dos projetos TeleVisões (UFF), Série Clube (UFF) e \#MUSEUdeMEMES (UFF). 
que falam sobre assuntos relevantes para o contexto históricocultural no qual os membros do fandoms estão inseridos.

Palavras-chave: Séries televisivas; Comunidades de fãs; Produção de fãs; Memes; Ecologia das mídias.

Abstract: Fans of TV series make extensive use of social networking sites as a tool to share materials produced by them, making the relationship between television and the digital medium increasingly complex. In this context, this paper aims to analyze what types of memes circulate in fan communities of television fiction series. For this, we conducted a research in two Brazilian fandoms of American series, Grey's MiiL gRaU and Game of Thrones Brasil L\&S. Framing them as a particular type of fan production, it is argued that the memes shared in these spaces could be categorized from two classifications: intratextual memes, which talk about the cultural object on which the fandom is centered; and extratextual memes, which talk about issues relevant to the historical-cultural context in which the members of the fandoms are inserted.

Keywords: TV series; Fandoms; Fan production; Memes; Media ecology.

Resumen: Los fans de las series de televisión hacen un uso extensivo de los sitios de redes sociales como una herramienta para compartir materiales producidos por ellos, haciendo cada vez más compleja la relación entre la televisión y el medio digital. En este contexto, este artículo propone analizar qué tipos de memes circulan en las comunidades de fans de las series de televisión. Para esto, se realizó una investigación en dos fandoms brasileños de series estadounidenses, Grey's MiiL gRaU y Game of Thrones Brasil L\&S. Tratándolos como un tipo particular de producción de fans, se argumenta que los memes compartidos en estos espacios podrían categorizarse a partir de dos clasificaciones: memes intratextuales, que hablan sobre el objeto cultural en el que se centra el fandom; y memes extratextuales, que hablan de temas relevantes al contexto histórico-cultural en el que se insertan los miembros de los fandoms.

Palabras clave: Series de televisión; Comunidades de fans; Producción de fans; Memes; Ecología de los medios. 


\section{Introdução}

Em 2015, os fãs brasileiros da série médica Grey's Anatomy (ABC, 2005-) ficaram de luto com a morte do neurocirurgião Derek Shepherd. Nos sites de redes sociais, muitos se mostravam indignados com a showrunner ${ }^{2}$ do programa, Shonda Rhimes. Foi a partir desse episódio que um conjunto de imagens começou a ser circulada pelo fandom ${ }^{3}$. Embora diferentes, elas compartilhavam semelhanças tanto no conteúdo quanto em sua estética: simulando uma rasura na tela de créditos da série e substituindo o termo "criado" para "destruído" por Shonda Rhimes. Nascia, assim, um meme. De forma similar, durante as eleições presidenciais brasileiras de 2018, os fãs da série televisiva Game of Thrones (HBO, 2011-2019) desenvolveram memes que se utilizavam dos elementos da narrativa para comentar sobre o contexto político do país. Nesse período, era comum encontrarmos usuários que indicavam o apoio a algum candidato por meio de sua foto de perfil em sites de redes sociais. Assim, inúmeras publicações buscavam simular essa estética e alinhar os posicionamentos políticos dos personagens da ficção seriada.

De fato, para os fãs de narrativas seriadas, cada frame, diálogo, personagem e demais aspectos da produção se torna matéria-prima para o desenvolvimento de memes. Em redes sociais, é possível notar que o público cativo de séries adotou o ambiente digital como ferramenta presente na experiência do consumo televisivo (ROSS, 2011) e usam esses espaços para fazer circular inúmeras peças que extrapolam o universo narrativo da obra da qual é derivada. Assim como as fanfics ${ }^{4}$ e as fanarts ${ }^{5}$, os memes têm se mostrado um tipo de produção amplamente circuladas nos fandoms de ficções seriadas. Embora sejam vistos como itens superficiais pelo senso comum, memes podem se configurar como importantes ferramentas para a construção de identidades coletivas (MILNER, 2016), além de vetores de circulação de sentidos que "podem ser espalhados, compartilhados, respondidos e comentados" (LAMERICHS et al., 2018, p. 186).

\footnotetext{
2 Showrunner é o produtor executivo (e muitas vezes criador) de uma série, abarcando tanto questões logísticas quanto criativas.

30 termo fandom surge a partir da aglutinação das palavras inglesas fan e kingdom, respectivamente traduzidos para fãs e reino.

4 Fanfics são textos ficcionais produzidos pelos fãs baseados em produtos midiáticos.

5 Fanarts são produções artísticas visuais criadas por fãs baseadas em algum produto midiático.
} 
Contudo, as pesquisas que se debruçam sobre memes derivados de produções televisivas geralmente se focam ou na relação dessas peças com o fluxo televisivo linear ou em memes que viralizam. Com isso, abre-se uma lacuna de análise a ser preenchida. Por um lado, as últimas duas décadas foram marcadas pela ascensão da televisão transmitida via internet, da distribuição de conteúdos audiovisuais a nível global e da espectatorialidade não linear (JENNER, 2018). Por outro, inúmeros exemplos de memes consolidados ficam circunscritos em comunidades de fãs, fazendo com que seu sentido permaneça reconhecido apenas pelos participantes desses espaços.

Tendo em vista o atual ecossistema televisivo e as dinâmicas organizacionais e de sociabilidade presentes em comunidades de fãs, este artigo busca observar que tipos de memes são circulados em fandoms de ficções seriadas televisivas. Devido ao caráter intertextual dessas peças (KNOBEL; LANKSHEAR, 2007), o eixo de análise se atenta para as formas pelas quais os sujeitos se utilizam dos elementos presentes nessas produções para gerarem seus próprios conteúdos. Em outras palavras: como os memes de séries dialogam com os elementos industriais e narrativos dessas produções, com outros produtos midiáticos e/ou com questões culturais desses sujeitos? Aqui, argumenta-se que os memes produzidos nesses fandoms deveriam ser vistos como um tipo específico de produção de fãs. Dentro das comunidades, eles funcionariam como comentários para gerar sentido não apenas sobre o que assistem como também do mundo em que vivem.

Para tanto, foi feita uma pesquisa de inspiração etnográfica entre julho de 2018 e maio de 2019 em dois grupos privados situados no Facebook, cada um deles voltado para uma série televisiva estadunidense diferente. A escolha se deu pela dinâmica de interação da plataforma, relevância da série e grau de atividade do fandom ${ }^{6}$. O primeiro fandom é o Grey's Miil gRaU, comunidade formada por fãs de Grey's Anatomy. A série é centrada na conturbada vida da cirurgiã Meredith Grey, que precisa lidar com a pressão e as exigências da profissão ao mesmo tempo em que administra os conflitos de sua vida pessoal. Composto

6 Apesar disso, neste trabalho não serão discutidas as especificidades das comunidades analisadas. De certo modo, as dinâmicas observadas não se diferem muito de outras características pontuadas por outros trabalhos semelhantes: os membros possuem códigos de conduta, gírias e mecanismos de distinção próprios (CAMPANELLA, 2012). Aqui, o trabalho foca-se apena nas questões envolvendo o desenvolvimento de memes nesses espaços. 
por cerca de 252 mil participantes ${ }^{7}$ a Grey's MiiL gRaU abarca conversas não só sobre Grey's Anatomy, mas também de outras produções feitas pela empresa de Shonda Rhimes, a Shondaland. Já o segundo é o Game of Thrones Brasil L\&S. Com 256 mil membros ${ }^{8}$, a comunidade é a maior do país voltada para Game of Thrones. Descrita pelos showrunners como "uma batalha épica por poder que se passa em um vasto e violento reino de fantasia"9, a série narra conflitos, guerras, alianças e traições entre famílias nobres na disputa do trono real a partir de perspectivas distintas. Desse modo, o fandom serve de espaço de discussão para os fãs de Game of Thrones e da saga literária escrita por George R.R. Martin na qual a narrativa se baseia.

O trabalho propõe a análise de memes circulados em fandoms a partir de dois eixos de classificação orientados pela relação entre os materiais feitos pelos fãs e o produto midiático no qual a comunidade é dedicada. De um lado estão os memes intratextuais, desenvolvidos pelos sujeitos com o intuito de comentarem sobre o objeto cultural de que gostam, como a narrativa ou os personagens. Do outro estão os memes extratextuais, que falam diretamente sobre acontecimentos ou temas relevantes para o contexto histórico-cultural em que os membros do fandoms estão inseridos. Aqui, o conceito de texto não deve ser entendido como um objeto estático, mas, sim, como algo experimentado no ato do consumo (GRAY, 2010) e que é lido a partir das comunidades interpretativas pelas quais os sujeitos se associam (FISH, 1980) ${ }^{10}$. Assim, busca-se compreender o consumo de série e o desenvolvimento de memes como ações inseridas em um circuito amplo, interligado e contínuo.

\section{Fandoms de séries televisivas em sites de redes sociais}

Assistir à televisão sempre foi uma atividade tanto individual quanto social (MITTEL, 2010). Desde sua criação, o aparelho televisivo serviu como um agregador de pessoas, não apenas na privacidade do

\footnotetext{
7 Dados coletados em 13 fev. 2020.

8 Dados coletados em 13 fev. 2020.

9 Variety - Fantasy sits on 'Thrones'. Disponível em: http://variety.com/2008/scene/markets-festivals/fantasy-sitson-thrones-1117995693/. Acesso: 18 set. 2020.

10 Aqui, entende-se que o texto não é formado apenas a linguagem verbal presente no objeto, mas sim pelo conjunto de elementos materializados na obra, como cenário, figurino e trilha sonora, por exemplo.
} 
ambiente doméstico familiar como também nos espaços públicos das cidades (BUONANNO, 2008, p. 14). Mas, embora muitas vezes vista em conjunto, a fruição televisiva não é homogênea. Trabalhos como os conduzidos por Ang (1991), por exemplo, buscam se desvencilhar de determinismos que encaixam programas televisivos entre a dicotomia de "bom" ou "ruim". A partir das correspondências enviadas por espectadores da série Dallas (CBS, 1978-1991), a autora percebeu que o envolvimento desse público com os personagens, especialmente os femininos, muitas vezes passavam pelas conexões que estes traçavam com suas próprias vidas. Assim, ao mesmo tempo em que os sentidos são encapsulados pelos produtores, os consumidores também possuem liberdade para múltiplas interpretações, seja pela via da assimilação, da negociação ou da indiferença (HALL, 2003).

Para Esquenazi (2011, p. 35-36), a chave para analisar a relação das séries com diferentes tipos de fãs se encontraria nas comunidades interpretativas às quais eles pertencem. Proposto por Fish (1980), comunidades interpretativas "são formadas por aqueles que compartilham as mesmas estratégias de interpretação" (p. 171) e se dão não na leitura convencional do texto, mas, sim, nas produções que são feitas a partir de seu consumo. Em outras palavras, as maneiras de se compreender um mesmo produto midiático seriam afetadas por outras características que compõem a identidade dos sujeitos tais como raça, gênero e sexualidade, o que explicaria por que certos grupos leem um mesmo texto de forma semelhante. Posteriormente, Jenkins (1992, p. 90) desenvolve o conceito ao dizer que, dentro dos fandoms, os fãs negociam a todo momento quais são as interpretações legitimadas. Porém, essa "maneira correta" não é estável. Os fãs discutem, disputam e divergem constantemente dentro das comunidades, apresentando perspectivas múltiplas, e até mesmo contrárias, sobre um mesmo produto cultural (CAMPANELLA, 2012).

Com a internet, os fãs também passaram a utilizar o meio digital em sua experiência de consumo. Já no início da década de 1990, era possível observar espaços para discussão online de programas televisivos (JENKINS, 1992, p. 115) e, ao longo dos anos, diversos sites, blogs e fóruns semelhantes foram criados como locais utilizados por fãs para debaterem sobre os episódios, armazenarem informações sobre o universo da narrativa ou compartilharem materiais que eram produzidos 
por eles (ANDREJEVIC, 2008). Em Beyond The Box (2011), Ross argumenta que a internet seria uma espécie de "bebedouro do novo milênio". A analogia proposta é derivada da teoria do efeito bebedouro: o ato de colegas de escritório se reunirem e socializarem nas pausas do trabalho. No caso do consumo televisivo, esse fenômeno está relacionado a conversas que nascem a partir dos programas de televisão: por exemplo, todos comentando sobre o último episódio de uma série de televisão famosa ou sobre o jogo que passou na noite anterior. A autora aponta que havia um receio de que a nichificação da televisão nos Estados Unidos fosse dificultar essa prática, já que "com tantos programas passando, quais são as chances do seu colega de trabalho assistir a mesma coisa que você?" (ROSS, 2011, p. 9). Todavia, o que realmente acontece é que essas discussões também passaram a ser travadas na internet: em comunidades de fãs, em sites especificamente dedicados a esse intuito e nos próprios sites de redes sociais dessas pessoas.

Em um dos eixos de discussão está a chamada TV Social (GALLEGO, 2013), termo intimamente relacionado com a convergência midiática e que procura abarcar práticas de sociabilidade no meio digital ligadas ao consumo televisivo, reforçando, assim, a ideia de experiência compartiIhada (SIGILIANO; BORGES, 2019). É comum, por exemplo, que emissoras, showrunners e atores incentivem a audiência a publicar comentários em seus perfis pessoais enquanto assistem à programação, prática conhecida e muitas vezes chamada de segunda tela (FINGER; SOUZA, 2012). Mas, por mais que "segunda tela" e "TV social" sejam termos tratados muitas vezes como sinônimos (ALMEIDA, 2018), eles se diferem na medida em que o primeiro se relaciona diretamente com um fenômeno que ocorre de forma síncrona com a transmissão televisiva, enquanto o segundo também abarca outras relações que surgem da intersecção entre televisão e redes sociais (GALLEGO, 2013). Dessa forma, há inúmeras outras práticas envolvendo a experiência de consumo televisivo para além daqueles ligados à segunda tela e que também fazem parte das dinâmicas de sociabilidade dessa audiência conectada.

Isso é posto em evidência quando observa-se o tipo de espectatorialidade feita por fãs brasileiros de séries estadunidenses. Historicamente, essas produções demoravam dias, semanas e até mesmo meses para serem exibidas na rede de televisão brasileira, o que fez com que a pirataria exercesse um papel fundamental (MEIMARIDIS; OLIVEIRA, 2018). Somado a isso, a expansão de serviços de televisão 
distribuída via internet como a Netflix complexificam o cenário atual, popularizando um consumo fora do fluxo linear. No Brasil, por exemplo, séries como Grey's Anatomy e Game of Thrones podem ser assistidas de diferentes maneiras: em emissoras de TV paga, em serviços de streaming, DVDs e por meio de downloads ilegais. Isso não significa dizer que a transmissão linear perdeu força. Assim como argumenta Buonanno (2008, p. 22), o surgimento de novos modelos televisivos não substitui os anteriores. Na verdade, novas e velhas formas de se fazer e ver televisão coexistem no ecossistema midiático contemporâneo.

\section{Memes e produção de fãs}

Fiske (1992) argumenta que a audiência se engaja com produções midiáticas a partir de três tipos diferentes de produtividade: semiótica, enunciativa e textual. A produção semiótica diz respeito aos sentidos e conexões feitas pelos sujeitos no momento do consumo. Ela é acionada a partir das comunidades interpretativas nas quais os sujeitos estão inseridos (ESQUENAZI, 2011) e ocorre no plano intrapessoal (SANDVOSS, 2013). Já a produção enunciativa se faz presente nas formas de interação que os indivíduos estabelecem por meio desses objetos. Ela se dá através de processos verbais, como conversas com outros fãs envolvendo os objetos que admiram; ou não verbais, como o uso de roupas com estampas de sua série de televisão favorita. No contexto digital, em especial nos sites de redes sociais, essa enunciação pode se dar de diferentes formas, como na estruturação dos perfis desses sujeitos ou nas associações feitas por eles.

Por fim, a produção textual é relacionada à confecção de objetos culturais feitos por fãs a partir do conteúdo original. Aqui, temos os mais diversos tipos de produtos: textos, ilustrações, filmes e uma variedade de outras peças que se apropriam desses produtos midiáticos e que selecionam os elementos que the são interessantes e criam novos sentidos. No cenário televisivo, especialmente no relacionado a indústria de ficção seriada, é comum que emissoras solicitem que os espectadores compartilhem suas produções textuais. Por exemplo, para comemorar a última temporada de Game of Thrones, a HBO pediu que os fãs da série publicassem em seus perfis no Twitter os materiais produzidos por eles com 
a hashtag \#ForTheThrone, a emissora, por sua vez, selecionava algumas das peças recebidas e as compartilhava nos canais oficiais da emissora.

Argumenta-se que memes circulados em fandoms seriam um tipo particular de produção de fãs. Em O Gene Egoísta (1976), o biólogo Richard Dawkins desenvolve o conceito de meme para tentar explicar processos de transformação cultural através da teoria evolutiva. $\mathrm{Na}$ visão do autor, os memes são ideias materializadas em artefatos ou comportamentos que são transmitidos entre os indivíduos através de processos de imitação. Nas décadas seguintes, o campo de estudos dos memes cresceu e o conceito foi debatido, disputado e complexificado em diversas áreas da academia (BLACKMORE, 2000; KNOBEL; LANKSHEAR, 2007; RECUERO, 2007), de forma que múltiplas perspectivas de análise surgiram.

Em Memes in Digital Culture, Shifman (2014) pontua que a definição de Dawkins já não dá conta de delimitar suficientemente o fenômeno, principalmente com as transformações trazidas pelo meio digital. $\mathrm{Na}$ internet, os artefatos culturais são copiados, encaminhados, remixados e espalhados através de processos variados de imitação e variação. Ao mesmo tempo que fãs encaminham memes que gostam em apenas um clique, não é incomum que esses sujeitos criem suas próprias versões, parodiando ou editando o conteúdo original. Para a autora, um meme é formado por

(a) um grupo de itens digitais que compartilham características comuns de conteúdo, forma e/ou posicionamento, que (b) foram criados com conhecimento mútuo de cada um e que (c) foram circulados, imitados e/ou transformados por muitos usuários através da internet (SHIFMAN, 2014, p. 41, tradução nossa).

Por isso, em vez de analisar memes como textos, imagens, vídeos ou qualquer outro tipo de formato como peças isoladas, é preciso entendê-los como pedaços de informações culturais que postas em conjunto, apresentam-se como um fenômeno compartilhado (SHIFMAN, 2014; CHAGAS, 2016). Por exemplo, as imagens dizendo que Shonda Rhimes "destruiu" Grey's Anatomy, sozinhas, são apenas peças feitas pelas fãs da série. Porém, quando levamos em conta que elas fazem parte de uma coletânea de materiais parecidos entre si, e que são circuladas de forma consciente por esses sujeitos, é que podemos categorizá-las como pertencentes a um meme. 
Ao contrário de fanfics e outros tipos de materiais confeccionados por um único sujeito (ou um grupo restrito de pessoas) e que podem ficar reservados apenas para a fruição de seus criadores, os memes presentes em fandoms se destacam por serem formados a partir de um conjunto de itens que guardam semelhanças estéticas ou discursivas e cujos sentidos são compartilhados pelos membros da comunidade. Nesse sentido, os memes são colocados a partir de uma dupla relação: por um lado, são criados individualmente pelos sujeitos; por outro, relacionam-se com o coletivo de interpretações sobre as narrativas, os personagens, os profissionais e demais fatores que envolvem os produtos midiáticos que admiram. Assim, relacionam-se diretamente com as comunidades interpretativas (FISH, 1980; JENKINS, 1992) em que esses fãs se enquadram.

\section{Categorizando memes}

Esforços para a categorização de memes já existem desde a época em que o conceito foi criado. Dawkins (1976) procurava delimitar o que assegurava o "sucesso" de um meme, ou seja, quais variáveis são acionadas para que ele se mantivesse vivo. O biólogo elenca como eixos centrais nesse processo a fecundidade, a fidelidade e a longevidade dessas peças, que são, respectivamente, a habilidade de inserção desse meme na sociedade, a precisão das cópias em se manterem fiéis às originais e a capacidade de permanecerem vivas durante um longo período de tempo. Recuero (2007), então, procura adaptar essas três características para o contexto das redes sociais, adicionando como uma quarta chave de análise o alcance. Inspirado na teoria dos laços, o alcance estaria relacionado à habilidade de percorrer diferentes grupos. Todo meme poderia ser analisado a partir de um desses quatro eixos e, assim, "dependendo de suas características, cada tipo de meme pode influenciar uma determinada rede de modo diferente" (RECUERO, 2007, p. 28). Enquanto para Dawkins (1976) os memes de sucesso seriam aqueles que se sustentam o mais fiel possível ao original, as variáveis propostas pela a autora abarcam justamente aqueles formados por intensas transformações e atravessamentos, comum nas dinâmicas do meio digital. 
Knobel e Lankshear (2007), embora não proponham uma taxonomia, apontam o humor, a intertextualidade e a justaposição como elementos que contribuem para o sucesso de um meme ${ }^{11}$. Os autores argumentam que a lógica da replicabilidade e da "mutação", na verdade, facilitariam a distribuição dessas peças e ajudariam a criar uma complexa rede de significados (p. 208-209). Esses acionamentos auxiliam a analisar não apenas as camadas de significado desses memes como também falam diretamente sobre quem são os sujeitos que os circulam. Em paralelo, ao analisar os memes dos debates presidenciais de 2014, Chagas (2016) observou que muitos eram carregados de intertextualidade. Esses atravessamentos, entretanto, não eram arbitrários, mas, sim, traçavam conexões com a própria grade de programação das emissoras que exibiam os debates.

Foi essa mesma abordagem de pesquisa, apoiada em um consumo televisivo pautado pela TV social, que serviu de base para a taxonomia de Almeida (2018). A autora observou como os fãs dos reality shows brasileiros se comportavam nas redes enquanto o programa estava sendo transmitido. Ancorada na definição de Dawkins (1976), Almeida (2018) propõe quatro tipos distintos, cada um deles exigindo um grau diferente de familiaridade e engajamento com as produções analisadas. Segundo ela, podemos separá-los entre: imersivos, que conversam diretamente com o que está sendo transmitido; disruptivos, que se utilizam do conteúdo exibido para tratar de outros assuntos e, portanto, rompem coma imersão televisiva; associativos, que traçam referências com outras produções midiáticas; e comparativos, que evidenciam a semelhança entre personagens ou situações presentes no programa.

Contudo, alguns elementos precisam ser pontuados. Em primeiro lugar, algumas das categorias se mesclam com outras já existentes dentro do campo dos estudos dos memes. Os associativos, por exemplo, podem muito bem ser definidos como memes carregados de intertextualidade. Já os comparativos, por definição, se enquadram como look-alikes, um padrão estético já reconhecido como um gênero de meme. Em ambos os casos, nada impede que peças enquadradas nessas categorias também se comportem como imersivos ou disruptivos.

11 Contudo, essas variáveis não devem ser encaradas como regras, especialmente a chave do humor. Embora haja uma tendência a categorizar memes como sinônimo de peças engraçadas, nem todos são pautados pelo viés cômico. 


\section{Metodologia}

A metodologia utilizada no trabalho foi inspirada em trabalhos como o de Campanella (2012), que procura mapear dinâmicas de sociabilidade em grupos de fãs no meio digital. Uma vez inserido nas duas comunidades ${ }^{12}$, Grey's MiiL gRaU e Game of Thrones Brasil L\&S, observei diariamente as publicações feitas na busca de identificar padrões de forma ou conteúdo. Nesse sentido, mantive um diário de campo atualizado constantemente e realizei inúmeras capturas de tela durante o período de análise. Em seguida, a partir das contribuições de Chagas (2016) e Almeida (2018), buscou-se desenvolver uma taxionomia visando categorizar os memes compartilhados pelos indivíduos dentro dos fandoms. As classificações criadas buscam abarcar tanto os memes circulados de forma síncrona com o consumo televisivo por meio da prática de segunda tela, quanto aqueles que são articulados em outros momentos de sociabilidade.

Dessa forma, os memes circulados nas comunidades de fãs são categorizados a partir de dois eixos, tendo em vista a relação estabelecida entre o meme e o objeto midiático no qual o fandom se estrutura. O primeiro é chamado de intratextual e pode ser definido como um meme que fala "para dentro" do produto que está sendo consumido. No caso das séries televisivas, são esses os memes criados para servir de comentário sobre a narrativa ou personagens do programa. Já o segundo é chamado de extratextual e é definido como um meme que se utiliza dos elementos presentes no produto midiático para se referenciar a elementos externos a ele, geralmente comentando sobre acontecimentos, outros objetos midiáticos ou demais assuntos que façam parte do cotidiano do fandom analisado.

Todavia, as duas classificações não são mutuamente excludentes. Memes intratextuais e extratextuais não devem ser vistos como pontos extremos de um mesmo espectro, mas, sim, como dois eixos articulados pelos fãs no momento da confecção do meme. As duas chaves de análise categorizam a circulação de memes desenvolvidos em fandoms através de sentidos distintos. No primeiro, o meme é centrado no

12 Nos grupos privados do Facebook, é necessário solicitar permissão para fazer parte da comunidade e observar as publicações. Ao contrário das fanpages, gerenciadas por um número restrito de administradores, nos grupos qualquer membro pode fazer uma publicação, ainda que também possam existir moderadores de conteúdo. 
objeto de idolatria do fandom, representado neste trabalho por Grey's Anatomy e Game of Thrones. No segundo, o meme é centrado no contexto cultural no qual a comunidade de fãs está inserida. Desse modo, a escolha dos conceitos parte do entendimento de memes como um gênero midiático próprio (KNOBEL; LANKSHEAR, 2007) que absorve e reflete a cultura dos sujeitos que os criaram.

A seguir, serão destrinchados os dois tipos de memes encontrados e como eles se relacionam com as práticas de consumo televisivo nesses fandoms. A escolha dos memes apresentados foi feita de forma subjetiva a partir do material bruto recolhido durante a pesquisa, selecionando imagens que retratassem de forma clara exemplos de memes intratextuais e extratextuais.

\section{Memes intratextuais}

Como mencionado, memes intratextuais falam diretamente com a narrativa das séries. Parte dessa categoria dialoga com os acontecimentos presentes nos últimos episódios. Tendo em vista que tanto Grey's Anatomy quanto Game of Thrones eram veiculadas semanalmente, esses materiais serviam para preencher o tempo de espera, de forma que os fãs comentavam sobre o que acabaram de assistir ao mesmo tempo em que se preparavam para os acontecimentos seguintes. Por isso, é bastante sintomático a presença esmagadora de memes que expressam reações, sejam eles trazendo comentários dos fãs desses produtos ou encenando os próprios personagens discorrendo sobre a história.

Em geral, esses memes possuem um tempo curto de vida. No início da oitava temporada de Game of Thrones, em 2019, o personagem Jon Snow (Kit Harington) conta para sua irmã, Sansa (Sophie Turner), que ele foi adotado e que seu pai biológico era, na verdade, o príncipe do reino onde vivem. Embora Jon tenha pedido segredo, Sansa espalha a notícia para outras pessoas logo na cena seguinte, o que rendeu inúmeras piadas dentro do fandom da série (Figura 1). Contudo, na semana seguinte esse tema parou de ser comentado dentro da comunidade. Esse padrão seguiu-se ao decorrer da pesquisa e era visível também na Grey’s MiiL GrAu. A cada novo capítulo, inúmeros memes surgiam e logo eram esquecidos quando o próximo é exibido e outros arcos 
narrativos vão ganhando atenção. Além disso, memes intratextuais podem servir também como termômetro para verificar a aprovação do enredo ou de algum personagem. Na comunidade de Grey's Antomy, boa parte dos memes circulados denotam a aceitação ou rejeição dos casais formados na série, como o caso dos médicos Jackson (Jesse Williams) e Maggie (Kelly McCreary), conforme descrito na Figura 2.

Figura 1

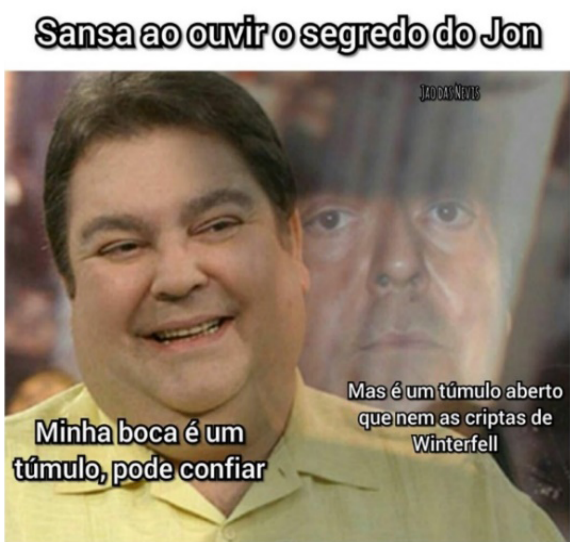

Fonte: Game of Thrones Brasil L\&S.
Figura 2

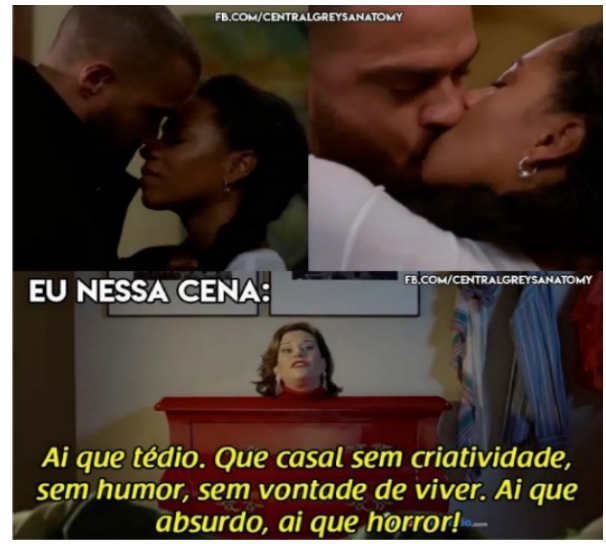

Fonte: Grey's MiiL GrAu.

Vale ressaltar a presença de intertextualidade nos memes citados. Tanto o apresentador Fausto Silva na Figura 1 quanto o comercial estrelado pela socialite Narcisa Tamborindeguy na Figura 2 têm relevância no contexto cultural do consumidor brasileiro, de forma que ambos são personalidades reconhecidas pelos membros dos fandoms. Conforme citado anteriormente, a intertextualidade é uma característica presente em diversos memes (KNOBEL; LANKSHEAR, 2007), o que exige uma análise atenta não apenas à relação do espectador com a série, mas, sim, a todo o circuito que envolve este consumo. Mas o fato dos exemplos citados serem repletos de intertexto não significa que, no final, os dois têm como objetivo discorrer sobre a narrativa da produção, pois, o primeiro faz piada sobre uma cena específica em Game of Thrones e o segundo reclama sobre o casal de médicos em Grey's Anatomy.

Ao mesmo tempo, nesses espaços também há uma enorme quantidade de memes que persistem em circulação por longos períodos. $\mathrm{Na}$ maioria das vezes eles fazem referência a momentos considerados marcantes para os fãs ou a traços recorrentes que compõe a personalidade 
dos personagens. Por exemplo, é recorrente na comunidade piadas sobre a morte do personagem George O'Malley, após ser atropelado por um ônibus (Figura 3), ou sobre os episódios finais da oitava temporada, no qual Cristina Yang (Sandra Oh), em estado de choque após se envolver em um acidente de avião, ficou desnorteada procurando seu sapato perdido (Figura 4). Novamente, há a presença de intertexto, uma vez que ambas as imagens são derivadas de memes pré-existentes. Na Figura 3, a legenda é retirada da expressão "Levanta a cabeça, princesa, senão a coroa cai”, derivada da 18ª edição do reality show Big Brother Brasil (TV Globo, 2001-). Já a Figura 4 faz piada com a estética dos cartões de "Bom dia", geralmente compartilhados via Whatsapp.

\section{Figura 3}

\section{Levanta a cabeça amigo se não o ônibus atropela.}

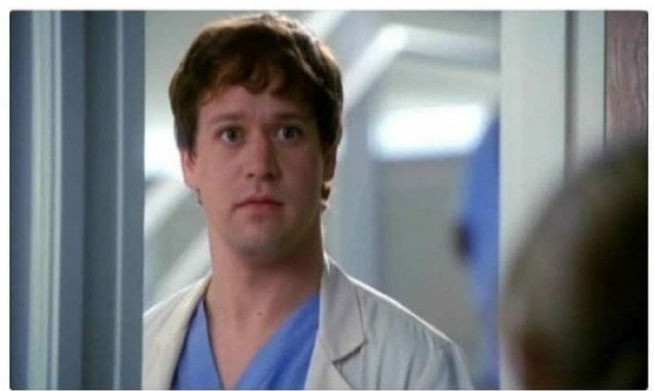

Fonte: Grey’s MiiL GrAu.

Figura 4

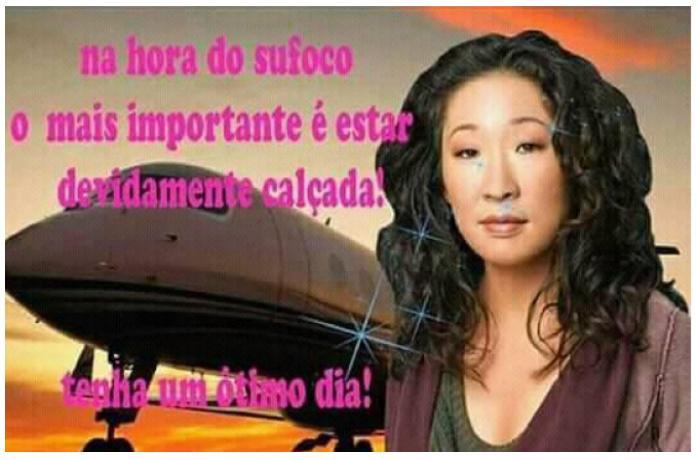

Fonte: Grey's MiiL GrAu. 
Com isso, aponta-se que memes intratextuais reforçam os argumentos de Jenkins (1992) ao demonstrarem diferentes posicionamentos por parte dos fãs. Tendo em vista que os fandoms não podem ser vistos como um bloco homogêneo de indivíduos, são produção de fãs como os memes que apontam para leituras variadas sobre um mesmo produto. Memes intratextuais, mesmo aqueles que são recortes reaproveitados de outros memes pré-existentes, se constituem como comentários acerca do produto admirado pelo fã. Ademais, esse tipo de meme também potencializa as afirmações de Ross (2011) sobre a teoria do efeito bebedouro no ambiente digital. Em um cenário marcado pela TV Social, os materiais circulados e os sentidos que são compartilhados funcionam não apenas como comentários explícitos sobre a programação televisiva, mas, também, engajando outros sujeitos a interagirem nas comunidades.

\section{Memes extratextuais}

Nem todos os memes que são produzidos pelos fãs de séries falam necessariamente sobre temas relacionados a essas ficções seriadas. Nos fandoms analisados, era comum que grandes acontecimentos e temas que impactassem a vida desses sujeitos repercutissem, de alguma maneira, através dos memes que eram circulados. Aqui, esses conteúdos são classificados como memes extratextuais. Por exemplo, durante a Copa do Mundo de futebol masculino, realizada entre os meses de junho e julho de 2018, uma gama de memes era criada a cada partida. Dentro das duas comunidades de fãs analisadas eram circulados materiais que combinavam elementos da série para comentar sobre os jogos da competição. Na Game of Thrones Brasil L\&S, era comum que os jogos fossem retratados a partir de acontecimentos da série. Um desses casos ocorreu ainda na primeira fase do campeonato, durante o confronto entre Alemanha e Coreia do Sul. A seleção alemã, que antes era vista como uma das grandes favoritas, acabou sendo eliminada pelos sul-coreanos. No Brasil, isso foi visto como um alívio, visto que a Alemanha havia eliminado o time brasileiro na última edição do torneio, como pode ser visto nas Figuras 5 e 6. 
Figura 5

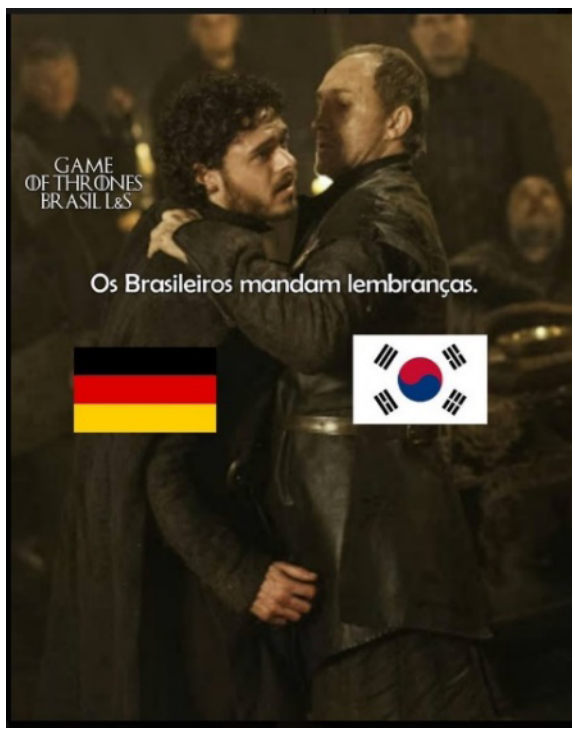

Fonte: Game of Thrones Brasil L\&S.
Figura 6

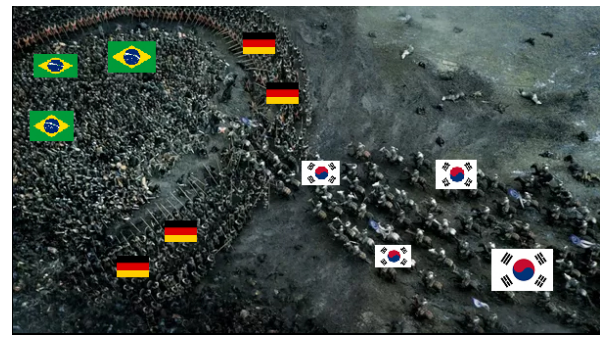

Fonte: Game of Thrones Brasil L\&S.

É interessante notar que as cenas utilizadas foram retiradas de momentos marcantes da série em diferentes temporadas e constroem um discurso que exalta a seleção sul-coreana pela vitória. Nesse sentido, memes extratextuais ainda são formulados a partir de códigos derivados dos produtos midiáticos (aqui, as séries), mas se utilizam desses códigos para discutirem assuntos relevantes para esses fãs. Assim, os memes extratextuais se posicionam como importantes peças para retratar temas referentes ao cotidiano desses indivíduos a partir da experiência do fandom.

Somado a isso, também é recorrente a utilização de memes que dialogam com aspectos da indústria de ficção seriada televisiva e dos hábitos de espectatorialidade desses fãs. Se um dos vértices do consumo de séries na atualidade encontra-se nas práticas dos fandoms (SILVA, 2014), são com esses memes que percebemos como os sujeitos se inserem nesse cenário. Após a divulgação da demissão das atrizes que interpretavam as médicas April Kepner (Sarah Drew) e Arizona Robbins (Jessica Capshaw) em Grey's Anatomy, os fãs da série se mostraram indignados com a despedida das personagens. É interessante notar os atravessamentos e conexões que são feitas pelos membros do fandom. 
De certo modo, as imagens ressaltam que os sujeitos estão cientes de processos de estruturação da narrativa e de como funcionam, pelo menos em parte, as dinâmicas da indústria de ficção seriada televisiva.

Figura 7

Viciados em Séries

@vicioemseries13

Sobre a saída da Jéssica e a Sara de Grey's Anatomy

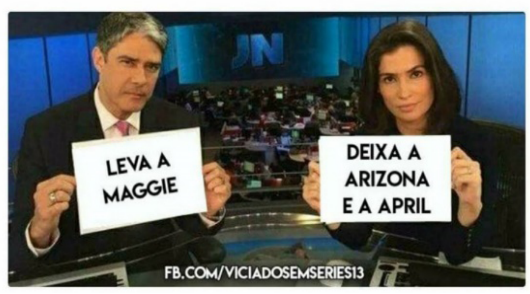

Fonte: Grey's MiiL GrAu.
Figura 8

eu na quinta feira

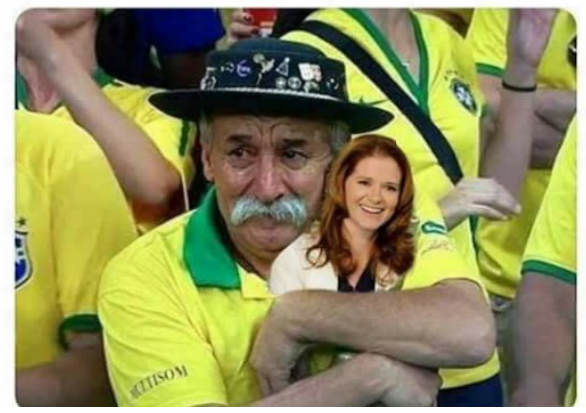

Fonte: Grey’s MiiL GrAu.

Assim como observado nos memes intratextuais, os memes extratextuais também podem ser repletos de intertexto. Apesar disso, os dois conceitos se diferem nas formas pelas quais a intertextualidade é articulada. As Figuras 5 e 6, por exemplo, mobilizam a imagem da série para ressaltar um grande evento compartilhado pelos membros do fandom. E mesmo as Figuras 7 e 8, embora também falem sobre a narrativa da série, apresentam em destaque a reação dos fãs enquanto comunidade. A partir de poucos casos que foram aqui apresentados, é possivel ter uma noção de como memes extratextuais podem se apresentar nas comunidades de fãs. Dessa forma, os memes que comentam sobre acontecimentos que impactam a vida dos sujeitos, assim como aqueles relacionados as práticas exercidas e objetos consumidos por eles, ajudam a reforçar uma visão que enquadra os fandoms não como grupos à parte da sociedade, mas sim como espaços que a integram e refletem suas dinâmicas (SANDVOSS, 2013). 


\section{Considerações Finais}

A televisão mudou drasticamente nas últimas décadas. Nesse sentido, transformações de ordem industrial, tecnológica e cultural têm afetado as formas de se produzir, circular e consumir séries televisivas. Quando se olha para a recepção, é possível notar que comunidades de fãs como a Grey's MiiL gRaU e a Game of Thrones Brasil L\&S configuram-se como locais no qual os sujeitos podem ampliar a experiência do consumo, servindo também como espaço para circulação de diferentes materiais criados pelos próprios fãs, como os memes. Os memes circulados em fandoms seriam um tipo particular de produção de fãs, que são formados por itens que guardam semelhanças estéticas ou textuais entre si e que só podem ser analisadas quando postas em conjunto.

A partir dessa definição, buscou-se categorizar os memes presentes nesses espaços tendo como eixo central de observação o conteúdo dessas peças e as diferentes maneiras pelas quais se interseccionam com a narrativa da produção. Dessa forma, eles foram divididos entre memes intertextuais, que se relacionam diretamente com a narrativa da série, e extratextuais, que dialogam com elementos presentes no contexto cultural dos fãs da produção. Contudo, não se pretende invalidar outras classificações, mas, sim, oferecer mais uma possibilidade de categorização. Ao mesmo tempo, embora tenha sido feito com base em comunidades voltadas para séries televisivas, acreditamos que essas variáveis também possam ser transportadas para fandoms de produtos midiáticos de outros formatos. De todo modo, analisar a criação e circulação de memes em fandoms pode nos oferecer caminhos produtivos para entender os complexos intercruzamentos feitos pelos sujeitos a partir de sua relação com os objetos dos quais são fãs.

\section{REFERÊNCIAS}

ALMEIDA, M. O COMPORTAMENTO MULTITELA NA TV SOCIAL: um estudo das práticas midiáticas em torno de The Voice Brasil e MasterChef Brasil. Tese de doutorado. Programa de Pós-graduação em Comunicação da Universidade Federal Fluminense, 2018.

ANDREJEVIC, M. Watching television without pity: The productivity of online fans. Television \& New Media, v. 9, n. 1, p. 24-46, 2008. 
ANG, I. Watching Dallas: Soap opera and the melodramatic imagination. Routledge, 1991. BLACKMORE, S. The meme machine. Oxford Paperbacks, 2000.

CAMPANELLA, B. Os olhos do grande irmão: uma etnografia dos fãs do Big Brother Brasil. Editora Sulina, 2012.

CHAGAS, V. Não tenho nada a ver com isso": cultura política, humor e intertextualidade nos memes das Eleições 2014. Internet e Eleições no Brasil. Curitiba: CPOP, 2016.

DAWKINS, R. The selfish gene. Oxford: OUP, 1976.

ESQUENAZI, J. As séries televisivas. Lisboa: Texto \& Grafia, 2011.

FINGER, C.; SOUZA, F. C. Uma nova forma de ver TV no sofá ou em qualquer lugar. Revista FAMECOS: mídia, cultura e tecnologia, v. 19, n. 2, 2012.

FISH, S. E. Is there a text in this class?: The authority of interpretive communities. Harvard University Press, 1980

FISKE, J. The Cultural Economy of Fandom. In: The Adoring Audience: Fan Culture and Popular Media, edited by Lisa A. Lewis. 30-49. New York: Routledge, 1992.

GALLEGO, F. Social TV Analytics: Nuevas métricas para una nueva forma de ver televisión. Index. Comunicación: Revista científica en el ámbito de la Comunicación Aplicada, v. 3, n. 1 , p. 13-39, 2013.

GRAY, Jonathan. Show sold separately: Promos, spoilers, and other media paratexts. NYU Press, 2010.

HALL, S. Codificação/decodificação. In: Da diáspora: identidades e mediações culturais. Belo Horizonte: Editora UFMG, p. 387-404, 2003.

JENKINS, H. Textual Poachers: Television Fans and Participatory Culture. New York: Routledge, 1992.

JENNER, M. Netflix and the Re-invention of Television. Springer, 2018.

KNOBEL, M.; LANKSHEAR, C. Online memes, affinities, and cultural production. In: A new literacies sampler. Nova lorque: Peter Lang, 2007.

LAMERICHS, N.; NGUYEN, D.; MELGUIZO, M. C. P.; RADOJEVIC, R.. Elite male bodies: The circulation of alt-Right memes and the framing of politicians on Social Media. Participations Journal of Audience \& Reception Studies, v 15, n.1, p. 180-206, 2018.

LOTZ, A. D. The television will be revolutionized. NYU Press, 2007.

MEIMARIDIS, M.; OLIVEIRA, T. Vingar e punir: motivações para a prática do spoiling. Comunicação, Mídia e Consumo, v. 15, n. 44, 2018.

MILNER, R. The world made meme: Public conversations and participatory media. Cambridge: MIT Press, 2016.

MITTELL, J. Television and American culture. Oxford University Press, USA, 2010.

RECUERO, R. Memes em weblogs: proposta de uma taxonomia. Revista FAMECOS: mídia, cultura e tecnologia, n. 32, 2007. 
ROSS, S. M. Beyond the box: Television and the Internet. John Wiley \& Sons, 2011.

SANDVOSS, C. Quando estrutura e agência se encontram: os fãs e o poder. C-Legenda-Revista do Programa de Pós-graduação em Cinema e Audiovisual, n. 28, p. 08-41, 2013.

SIGILIANO, D.; BORGES, G. As discussões sobre a décima temporada de The X-Files na social TV: uma análise do backchannel da décima temporada. Contemporânea, v. 17, n. 1, p. 29-52, 2019. SILVA, M. V. B. Cultura das séries: forma, contexto e consumo de ficção seriada na contemporaneidade. Galaxia, n. 27, 2014.

SHIFMAN, L. Memes in digital culture. Cambridge: MIT Press, 2014.

Recebido em: 09/02/20

Aprovado em: 20/12/20 


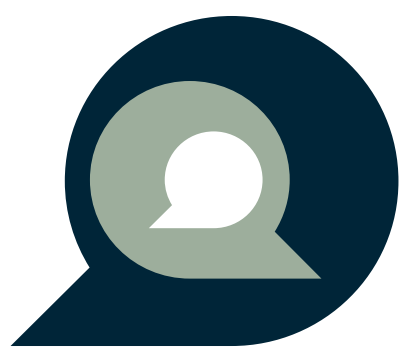

